\title{
EXPERIMENTAL STUDY OF QUENCHING PROCESS DURING BOTTOM REFLOODING USING “QUEEN” TEST SECTION
}

\author{
Mulya Juarsa, Anhar R. Antariksawan, Joko P., Ismu H., \\ Edy S. and Kiswanta \\ Risk Analysis and Accident Mitigation Division \\ Nuclear Safety Technology Development Center(P2TKN) - BATAN \\ Kawasan PUSPIPTEK Serpong Building No.80, Tangerang 15310 INDONESIA \\ Tel: (62)-21-7560913, Fax: (62)-21-7560912, e-mail: myjuar@yahoo.com \& anharra@centrin.net.id
}

\begin{abstract}
EXPERIMENTAL STUDY OF QUENCHING PROCESS DURING BOTTOM REFLOODING USING “QUEEN" TEST SECTION. Phenomenon of quenching of hot fuels in core during bottom reflooding following loca event is investigated in order to understand the performance cooling process. the study is conducted experimentally using queen test section which allow study of rod surface temperature histories based on which the heat fluxes are estimated. the visual observation is also done to study the boiling regimes. the test variables are initial rod temperature, i.e. $400^{\circ} \mathrm{c}, 500^{\circ} \mathrm{c}$ and $600^{\circ} \mathrm{c}$, and coolant flow rate, i.e. $0,01 \mathrm{~kg} / \mathrm{s}, 0.02 \mathrm{~kg} / \mathrm{s}$ and $0.04 \mathrm{~kg} / \mathrm{s}$ with constant water inlet temperature of $30^{\circ} \mathrm{c}$. the results shows different heat transfer regimes such as film boiling, transition boiling, nucleate boiling and convective single phase heat transfer regimes. for specified initial rod temperature, the higher flow rate provides high rewet velocity and higher maximum heat flux, then quenching process is more effective.
\end{abstract}

Keywords: quenching, reflooding, experiment

\section{INTRODUCTION}

One of the fundamental safety functions in nuclear power plant (NPP) design is ensuring the core cooling. Following the blow-down phase of postulated loss of coolant accident (LOCA) in a NPP, the fuel clad temperature may rise quickly to a high value (around $930^{\circ} \mathrm{C}$ at PWR), so that the injected water from emergency core cooling system (ECCS) during reflooding phase may not wet the clad immediately on coming into contact due to its sudden evaporation. As fuel cladding temperature decreases, the water could wet the surface and moves on. Then, quenching the clad is essential for effective heat removal by the emergency coolant; the situation will be worst by resulting on core melt down due to degradation on heat removal from the very hot fuels.

Thus, study on heat transfer and hydrodynamic aspects of quenching phenomenon during reflooding process following injection of ECCS, have been performed since three decades using experimental model or analytical model [1-5]. Extensive studies have continued due to complexity phenomenon and to various influencing parameters. The most recent studies focused on the real fuel bundle geometry and the effect of non-condensable gas. X.C. Huang et al. [6] has been doing a quenching experimental using 
cylinder's copper at pressure range between 1-10 bars and mass flux variations from $25 \mathrm{~kg} . \mathrm{m}^{2}$.s until $150 \mathrm{~kg} . \mathrm{m}^{2} . \mathrm{s}$. He analyzed boiling curve from heated rod temperature temperature's data. L. Spood et al. [7] observed characteristic on temperature transient increasing at heated rod as fuel rod simulation of PWR type. W.J. Green and K.R. Lawther [8] using ACTOR Freon loop was investigate transient heat transfer at low temperature on regime flow boiling. P.K. Das et al. [9] was conduct some experimental to investigated rewetting phenomena on hot vertical annular channel, his research have a good argument to use in rewetting analysis in present experiment, even though it's not similar.

The thermal-hydraulics behavior of hot vertical rod cooling encountered during ECCS injection could be flow direction-dependent. During cooling process, for a given initial temperature along rod length, the rewetting velocity may depend on the initial rod temperature. On the other hand, water coolant mass flow rate and temperature may become an important parameter in the average rewetting velocity for a given set of initial condition. In the light of providing contribution to the reactor thermal-hydraulic safety, especially concerning fuel rod quenching process, one test section so-called QUEEN (Quenching Experiment) was constructed. This test section is coupled to BETA's loop (Boucle d'Experimental Termohidraulique Appliqué). The heat transfer characteristics of during cooling of heated rods installed in QUEEN test section, i.e. single rod and four rods bundle configuration, have been studied previously by M. Juarsa et al. [10]. Then, R. Ruliandini studied the rewetting velocity using QUEEN test section [10-11]. The present work is aimed to provide the experimental results using single rod with the variable parameters of initial rod temperature and coolant flow rate and as preliminarily interpretation of rewetting velocity and boiling heat transfer in such case and also the effects of initial rod temperature and flow rates on heat transfer during quenching process.

\section{EXPERIMENTAL SET-UP}

\section{QUEEN test section description}

The diagram and photograph of the experimental set up used for quenching during bottom reflooding experiment is shown in Figure 1a and Figure 1b. 


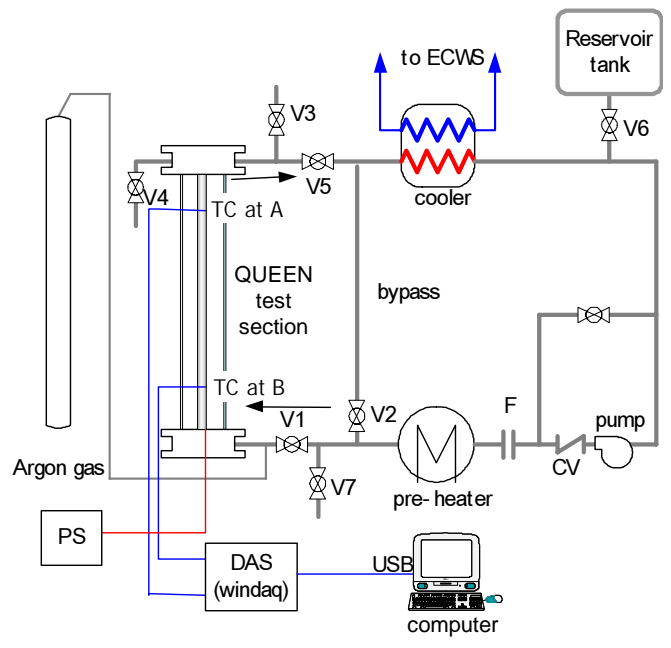

Figure 1a. Beta loop flow diagram.

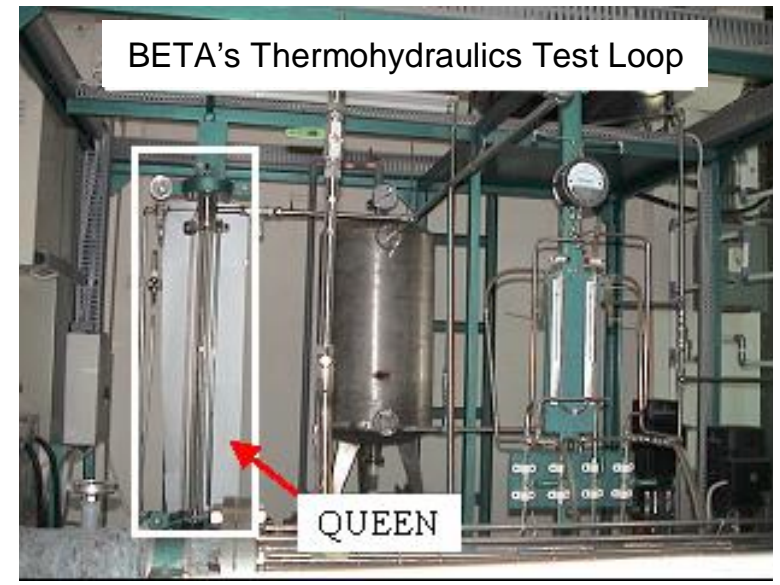

Figure 1b. BETA loop photograph.

The set up consist mainly of a source of power supply (PS), a source of de-mineralized water supply (in reservoir tank), QUEEN test section and a data acquisition system (DAS) including computer as data recorder and monitoring. The QUEEN test section comprises a single stainless steel (SS 304) tube with $9.8 \mathrm{~mm}$ outer diameter and $7.4 \mathrm{~mm}$ inner diameter. A coil heater was installed inside SS 304 tube, which becomes heated rod, with length of $700 \mathrm{~mm}$. Two K-type thermocouples (TC) are installed at two different positions of rod wall to measure the wall surface temperature. The positions of two TC are shown in Figure 2. 


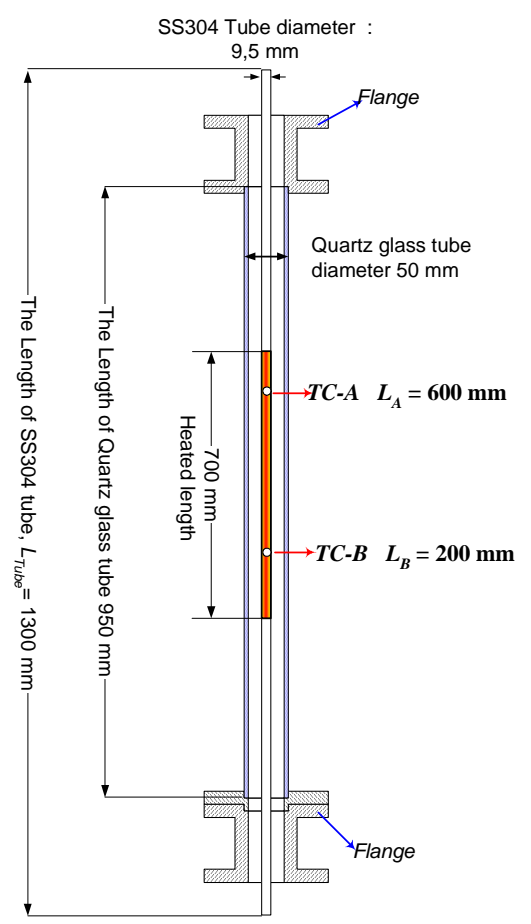

Figure 2. The QUEEN test section.

Thermocouples signals are recorded using data acquisition system (DAS) of WinDAQ ${ }^{\circledR} \mathrm{T} 1000$ which is connected to a personal computer with sampling rate of 5 data per second. Observation of the boiling heat transfer during cooling process is conducted using a digital video camera.

\section{Experimental procedure and range of parameters}

Before starting the experiment, heated rod is heated up gradually until the desired initial temperature achieved. In this experiment, three initial wall rod temperatures are designated, i.e. $400^{\circ} \mathrm{C}, 500^{\circ} \mathrm{C}$ and $600^{\circ} \mathrm{C}$. After initial wall rod temperature is reached, the power supply is switched off. The Argon gas flowing to keep rod surface from burn-out during heating process was turn off. The experiment was conducted by switching on the valve (V1) open and letting sub-cooled water $\left(30^{\circ} \mathrm{C}\right)$ to flow in from the bottom of the test section. For each initial rod temperature, water mass flow rate was varied, i.e. $0.01 \mathrm{~kg} / \mathrm{s}, 0.02 \mathrm{~kg} / \mathrm{s}$ and $0.04 \mathrm{~kg} / \mathrm{s}$. 


\section{RESULTS AND DISCCUSIONS}

\section{Cooling process and temperature histories}

Figure 3, 4 and 5 show the heated rod wall temperature histories during cooling process for initial temperature $400^{\circ} \mathrm{C}, 500^{\circ} \mathrm{C}$ and $500^{\circ} \mathrm{C}$, respectively. In each figure, it is shown the experimental results for three different coolant flow rate. The dashed line curve shows the temperature recorded by the lower TC (TC at B, $200 \mathrm{~mm}$ from bottom).

From temperature histories, it could be observed that the cooling process in the lower part is different with the upper part of the heated rod. In the lower part, initial temperature is lower than the upper part. As consequence, the coolant rewets the rod faster, which leads to a rapid temperature drop.

Prior to the rewetting of heated wall by the coolant, the rod cooling is occurred through radiation process from the rod wall to the air in quartz glass tube. Because the radiation heat flux is relatively small, the wall temperature decreases slowly; the higher initial temperature, the faster temperature decreases as observed from temperature histories. It is obvious because the radiation heat flux is equivalent to the fourth power of rod temperature as given by (see Nomenclature for symbol used):

$$
q_{\text {rad }} \approx\left(T_{w}^{4}-T_{\text {air }}^{4}\right)
$$

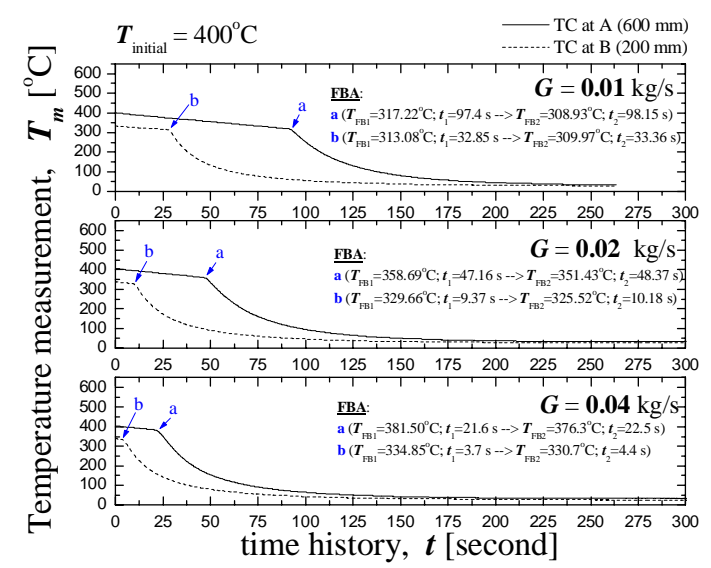

Figure 3. Transient temperature for $\boldsymbol{T}_{\text {initial }}=400^{\circ} \mathrm{C}$ 


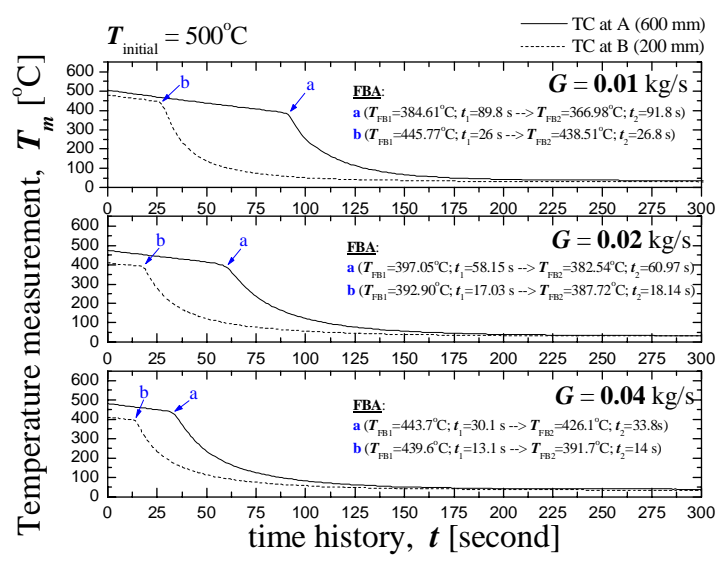

Figure 4. Transient temperature for $\boldsymbol{T}_{\text {initial }}=500^{\circ} \mathrm{C}$

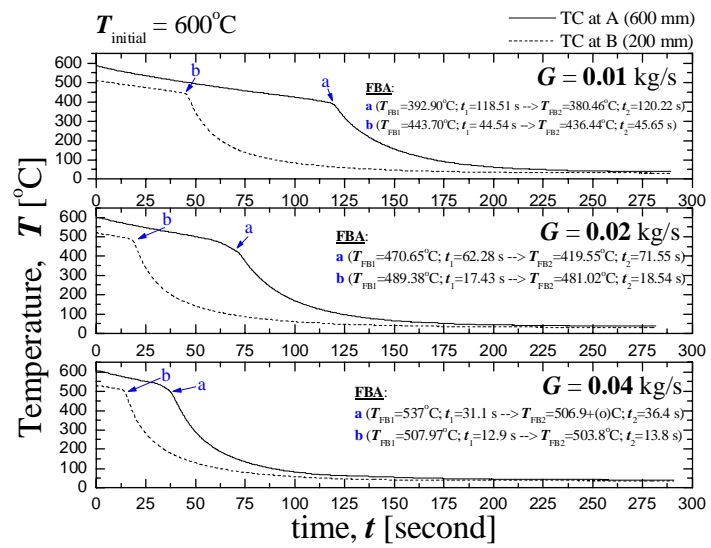

Figure 5. Transient temperature for $\boldsymbol{T}_{\text {initial }}=600^{\circ} \mathrm{C}$

As the coolant flows and floods the quartz glass tube, the rod temperature decreases and the quench front progresses. During the cooling process, the heat transfer regime changes from radiation heat transfer to film boiling heat transfer, transition, nucleate and convective heat transfer regime. The heat transfer regime change is observed easily at higher temperature and flow rate (as seen in Fig. 5), because at lower temperature the minimum film boiling temperature is closed to the initial rod temperature and attained quickly. The inflected curve indicates the change from radiation heat transfer to film boiling (marked by point $a$ and $b$ ); the transition regime, in all cases studied, is quite short due to relatively high forced flow. The nucleate boiling is indicated by high gradient temperature due to high heat flux to the coolant. 
When the temperature of heated rod close to the coolant temperature, the heat transfer enters into convective heat transfer regime; it is indicated by smooth curve.

The heat transfer regime during cooling process could be seen from visual observation as shown in Figure 6. This figure shows the experimental results of test with initial rod temperature of $600^{\circ} \mathrm{C}$ and water mass flow rate $0.02 \mathrm{~kg} / \mathrm{s}$. When the rewet point approached, the heated rod temperature begins to drop due to increased axial heat conduction along the heated rod. Then, quenching begins leading to a rapid temperature drop, knowing as transition boiling process. After the surface was rewetted, as transition boiling, the heated rod was cooled down to bulk temperature quickly.

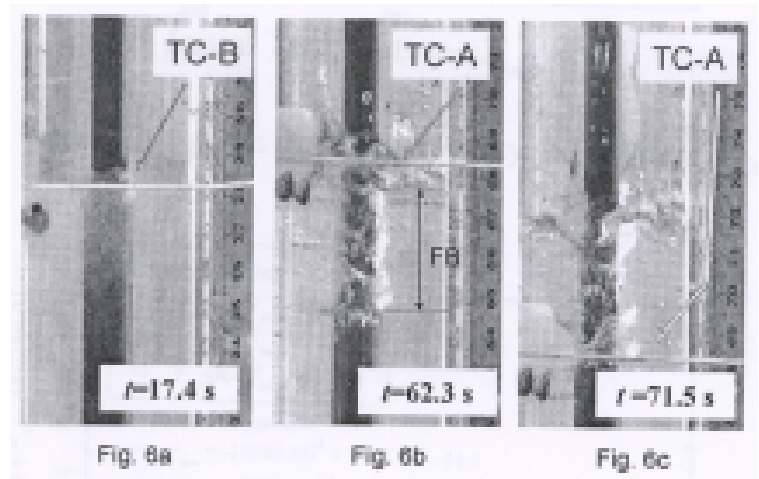

Figure 6. Boiling Visualization at $\boldsymbol{T}_{\text {initial }}=600^{\circ} \mathrm{C}$ and $\boldsymbol{G}=0.02 \mathrm{~kg} / \mathrm{s}$

Figure 6a shows the quenching process at $t=17.4 \mathrm{~s}$ after water entering the bottom of QUEEN test section. Thermocouple at point B (200 $\mathrm{mm}$ ) was covered by water and it is observed that film boiling begins to occur. While the coolant continue to flow upward at constant velocity, the rod surface temperature in upper part of point B remains higher than the minimum film boiling temperature, the surface remains dry, and the quench front moves behind the coolant bulk. Consequently, we can observe film boiling region (FB). Figure $6 \mathrm{~b}$ shows the condition at $t=62.3 \mathrm{~s}$, the length of film boiling is about $30 \mathrm{~mm}$. Following the rod temperature decrease, the film collapse, the surface is wetted and the quench front moves upward. Then, as shown in Fig. $6 c(t=71.5 \mathrm{~s})$, water begins to rewet point A $(600 \mathrm{~mm})$. As the surface temperature continues to decrease, film no longer exists and the cooling is governed by nucleate and convective boiling.

\section{Average rewetting velocity}

Rewetting velocity is defined as the velocity at which the rod surface is wetted during quenching process. In order to determine average rewetting velocity based on experimental results, a simple calculation was performed. 
Rewetting velocity is calculated by dividing thermocouple location distance between the point $\mathrm{A}$ and $\mathrm{B}$, i.e. $400 \mathrm{~mm}$, with time interval between first rewet at the point $\mathrm{A}$ and second rewet at the point $\mathrm{B}$ as follows:

$$
v_{\text {rew }}=\frac{\Delta L}{\Delta t}=\frac{400}{\Delta t}[\mathrm{~mm} / \mathrm{s}]
$$

Time interval between two rewetting for each initial temperature was determined using temperature history curve. Figure 7 shows the average rewetting velocity versus initial temperature, and Figure 8 shows the curve of rewetting velocity versus water mass flow rate.

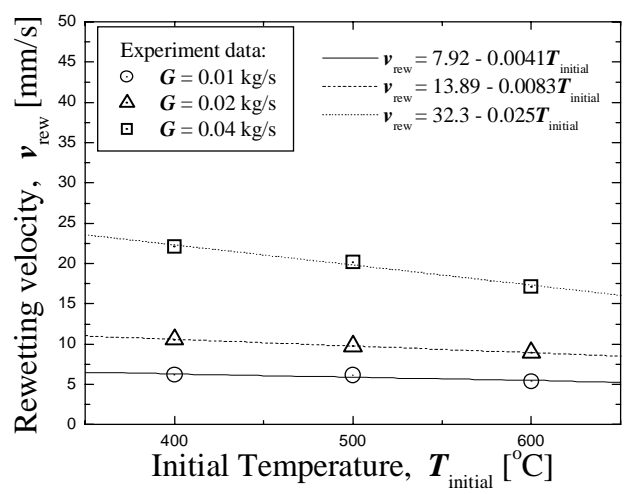

Figure 7. Average rewetting velocity for different $\boldsymbol{T}_{\text {initial }}$

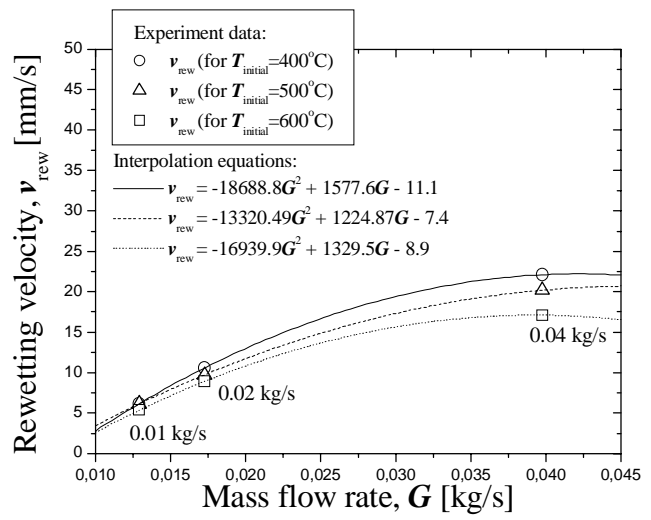

Figure 8. Average rewetting velocity for different $\boldsymbol{G}$.

The calculation results shows that both of initial temperature and water mass flow rate have significant influence to rewetting velocity. But, if we can see from Figure 7, the average rewetting velocity gradient increase with mass 
flow rate and decreases along with the increasing of initial temperature. Interpolation equation also pointed out using linier regression to keep calculation results in equation form. Figure 8 shows that average rewetting velocity tends to reach constant value. But, this trend must be validated experimentally using higher value of mass flow rate.

\section{Heat flux calculation}

Heat flux during quenching process is estimated based on the temperature history and visual observation. Approach has been taken to divide the quenching process into two broad boiling regimes, i.e. film boiling (including radiation heat transfer) and nucleate boiling regime; the transition boiling regime is neglected due to difficulty of its determination. From the temperature history (see Figures 3, 4 and 5), the change of radiation heat transfer region, film boiling regime and nucleate boiling regime is differentiated by the change of the temperature gradient. Then, the heat fluxes in film boiling and nucleate boiling are calculated using Bromley correlation [13] and Murase correlation [14], respectively, as follows:

Bromley correlation for film boiling:

$$
q=K . \Delta T_{w}^{0.75}
$$

where $\quad K=C_{B}\left[\frac{k_{g}^{3} g \rho_{g}\left(\rho_{f}-\rho_{g}\right) \Delta h_{f g}}{\mu_{g} L_{e}}\right]^{0.25}$

and Murase et al. correlation for nucleate boiling:

$$
q=K \cdot \Delta T_{w}^{n_{1}+1}
$$

where $K=C_{M} \frac{k_{f}^{n_{1}+1} \cdot L_{h}^{n_{2}-1}}{\left[\rho_{g} \Delta h_{f g} v_{f}\right]^{n_{1}}}\left(\frac{P}{\sigma}\right)^{n_{2}}$

Using the constant values of $C_{\mathrm{B}}=0.067, C_{\mathrm{M}}=2.2, n_{1}=-0.1 n_{2}=0.32$, $P=0.1 \mathrm{MPa}, \rho_{\mathrm{f}}=957.85 \mathrm{~kg} / \mathrm{m}^{3}, \rho_{\mathrm{g}}=0.5956 \mathrm{~kg} / \mathrm{m}^{3}, \sigma_{\mathrm{f}}=0.0589 \mathrm{~N} / \mathrm{m}$, $v_{\mathrm{f}}=2,97 \times 10-7 \mathrm{~m}^{2} / \mathrm{s}, c_{\mathrm{p}}=2.029 \mathrm{~kJ} / \mathrm{kg}, \Delta h_{\mathrm{fg}}=2257 \mathrm{~kJ} / \mathrm{kg}, L_{\mathrm{e}}=0.01574 \mathrm{~m}$, $L_{\mathrm{h}}=0.7 \mathrm{~m}$ and the surface temperature measured, we obtain for the initial rod temperature of $600^{\circ} \mathrm{C}$ and three variation of mass flow rate as shown in Figure 9. 


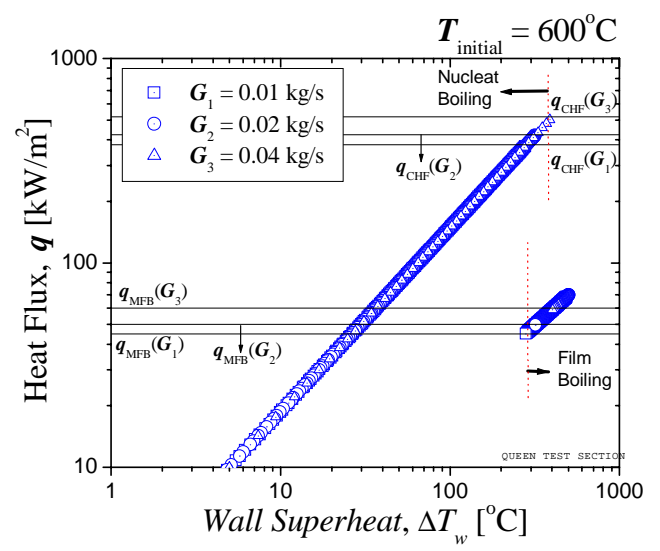

Figure 9. Estimated heat fluxes during quenching process for different flow rates.

Three heat flux curves as function of wall superheat of three different flow rates coincides each others. It is because the calculations use the correlation that only function of wall superheat. The differences among them are at the maximum heat fluxes in the nucleate boiling regime (called critical heat flux, $\left.\mathrm{q}_{\mathrm{CHF}}\right)$ and the heat fluxes at minimum film boiling values $\left(\mathrm{q}_{\mathrm{MFB}}\right)$. The higher mass flow rate, the higher critical heat flux and minimum film boiling flux. The Table 1 shows calculated critical heat flux and minimum film boiling flux for three different initial rod temperatures and flow rates.

Table 1. Critical heat flux and minimum film boiling flux for different initial rod temperatures and flow rates.

\begin{tabular}{|c|c|c|c|}
\hline $\boldsymbol{T}_{\text {in }}[\mathrm{oC}]$ & $\boldsymbol{G}[\mathrm{kg} / \mathrm{s}]$ & $\boldsymbol{q}_{\mathrm{CHF}}\left[\mathrm{kW} / \mathrm{m}^{2}\right]$ & $q_{\mathrm{MFB}}\left[\mathrm{kW} / \mathrm{m}^{2}\right]$ \\
\hline \multirow{3}{*}{400} & 0.01 & 286.0 & 36.0 \\
\cline { 2 - 4 } & 0.02 & 344.0 & 41.5 \\
\cline { 2 - 4 } & 0.04 & 381.0 & 45.0 \\
\hline \multirow{3}{*}{500} & 0.01 & 344.0 & 43.0 \\
\cline { 2 - 4 } & 0.02 & 377.0 & 45.5 \\
\cline { 2 - 4 } & 0.04 & 424.0 & 50.0 \\
\hline \multirow{3}{*}{600} & 0.01 & 379.0 & 45.0 \\
\cline { 2 - 4 } & 0.02 & 424.0 & 50.0 \\
\cline { 2 - 4 } & 0.04 & 520.0 & 60.0 \\
\hline
\end{tabular}




\section{CONCLUSIONS}

The experimental study was conducted to investigate a quenching phenomenon during bottom reflooding of single heated rod using QUEEN test section. The experimental results can show the different heat transfer regime during heated rod quenching process, i.e. radiation, film boiling, transition boiling, nucleate boiling and convective boiling heat transfer regimes. The effects of initial rod temperature and coolant mass flow rate on quenching process, average rewetting velocity and heat flux are studied. The higher initial rod temperature, film boiling occurs longer and film boiling length increases, but the average rewetting velocity decreases for given coolant mass flow rate. For specified initial rod temperature, the rewetting velocity increases naturally with mass flow rate. The maximum heat flux is higher for higher coolant mass flow rate and the initial rod temperature. Then, for specified initial rod and coolant inlet temperature, the higher coolant flow rate provides better quenching process (higher heat flux and faster cooling).

\section{ACKNOWLEDGMENTS}

Thanks to Mr. Alfahari Mardi as the head of P2TKN to support for conducting this research project. Great thank to Mr. Puradwi I.W., head of division, for his advices and support and also to Mr. Khairul Handono for his kind help during the execution of experiments.

\section{NOMENCLATURES}

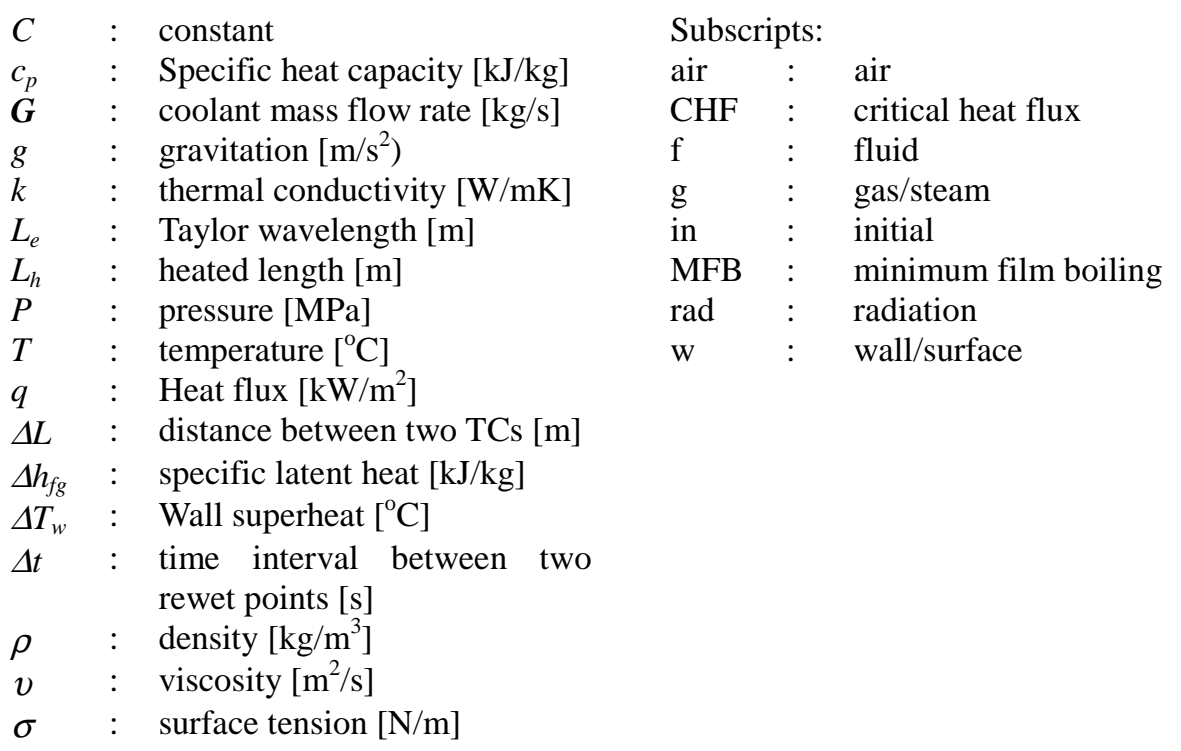




\section{REFERENCES}

1. DUFFEY, R.B., PORTHOUSE, D.T.C, The Physics of Rewetting in Water Reactor Emergency Core Cooling, Nuclear Engineering and Design, No.25, 379-394, (1973).

2. CONEY, M.W.E., Calculations on the Rewetting of Hot Surfaces, Nuclear Engineering and Design, No.31, 246-259, (1974).

3. BLAIR, J.M., An Analytical Solution to a Two-Dimensional Model of the Rewetting of A Hot Dry Rod, Nuclear Engineering and Design, No.32, 159-170, (1975).

4. PIGGOT, B.D.G., and PORTHOUSE, D.T.C., A Correlation of Rewetting Data, Nuclear Engineering and Design, No.32, 171-181, (1975).

5. CHAN, S.H., GROLMES, M.A., Hydrodynamically-Controlled Rewetting, Nuclear Engineering and Design, No.34, 307-316, (1975).

6. X.C.HUANG et al., "Quenching experiments with a circular test section of medium thermal capacity under forced convection of water", International Journal of Heat Mass Transfer, Vo.37, No.5, pp.803-818, (1994).

7. L. SEPOLD et el., "Reflooding Experiments with LWR-type Fuel Rod Simulators in the QUENCH Facility", Nuclear Engineering and Design 204, pp.205-220, (2001).

8. W.J. GREEN and K.R. LAWTHER, "An Investigation of Transient Heat Transfer in The Region of Flow Boiling Dryout with Freon-12 in A Heated Tube", Nuclear Engineering Design 55, pp. 131-144, (1979).

9. P.K. DAS, "Boiling Heat Transfer from a Single Fuel Pin Simulator during Rewetting by Bottom Flooding", Proceedings of ICONE 9, Nice (France), 8 - 12 April, (2001).

10. M. JUARSA et al., "Experimental Study on Boiling Heat Transfer during Reflooding Experiments Using QUEEN Test Bundle," $9^{\text {th }}$ Seminar on NPP Safety and Technology, Jakarta, August 20, (2003) (In Indonesian).

11. M. JUARSA et al., "Boiling Heat Transfer Analysis in Reflooding Experiments Using QUEEN Test Bundle," Scientific Presentation and Meeting on Basic Research of Nuclear Science and Technology, P3TM-BATAN, Yogyakarta, July 13, (2004) (In Indonesian).

12. R. RULIANDINI, "Study on Rewetting Phenomenon during Quenching Process through Experimental Simulation using BETA Test Loop," Bachelor Research Report, University of Padjadjaran, Bandung, (2004). 
13. L.A. BROMLEY, "Heat Transfer in Stable Film Boiling," Chem. Eng. Prog., Vol. 46, p. 221, (1950).

14. MURASE et al., "Heat Transfer Model in Narrow Gap," Proc. of $10^{\text {th }}$ ICONE, (2001). 